\title{
The medicine drug market and its reforms
}

\author{
Prof. Carine MILCENT \\ Carine.milcent@psemail.eu \\ CNRS - PSE
}

In OECD countries, spending on medicine drugs accounted for approximately $17 \%$ of total health spending or $1.5 \%$ of gross domestic product (GDP) in 2009. ${ }^{1}$ That same year, spending on pharmaceutical products in China represented $43 \%$ of total healthcare expenditures (Yip et al, 2012) $)^{2}$.

Aware of the issue, the Chinese government has been trying to fix this particularity. His main tool has been to set up a list of key drugs that are considered essential. The main idea of this system is that these drugs have to be accessible to everyone, with a regulated price to be kept as low as possible.

To keep prices low, procurement is made through centralized bidding, provinces purchase through the central level and pharmaceutical companies deliver directly to medical facilities. Yet, on the field, the reality remains sometimes complex. In this chapter, we will see that on the field, there are different ways to go around these constraints.

\section{Background}

China is the second largest pharmaceutical market in the world. This sector has been growing by $21.4 \%$ between 2002 and 2012 .

China is also one of the heaviest users of antibiotics, with $70 \%$ of prescriptions containing antibiotics. ${ }^{3}$ One of the reason that explains this situation is the way hospitals are financed in China. Indeed, in case of hospital admission, whatever the country, the patient is quite passive. He usually doesn't really take part in the decision to take a certain treatment. On the other hand, there exists a strong difference between Asian and Western countries as far as outpatients are concerned. The physician is not consulted in his practice but within a hospital. Medicine are then supplied at the end of the consultation, the patient having no real choice whether to purchase them or not. He doesn't have to go to a separate pharmacy to buy them either. This empowers

1 OECD. Value for money in health spending. Paris: OECD Health Division, 2010

2 Yip, Winnie Chi-Man, William C Hsiao, Wen Chhen, Shanlian Hu, Jin Ma, and Alan Maynard. "Early Appraisal of China's Huge and Complex Health-Care Reforms." The Lancet 379 no 9818 (2012): 833-842.

${ }^{3}$ Reynolds L, McKee M: Factors influencing antibiotic prescribing in China: an exploratory analysis. Health Policy 2009, 90(1):32-36. 
the physician with a dual role, both supplier of health services and supplier of health goods. At the end of the consultation, the invoice includes both, with a split that is often hard to make.

As a consequence, the price asked for medicine drugs can become an adjustment variable to the decrease of other funding for the hospital. The phenomenon has been empirically described (Eggleston 2008). A few years ago, drugs accounted for almost half of health spending. Overprescription and over-use of high tech diagnosis equipment are often pointed as one of the mains source of soaring health costs (Eggleston et alii, 2008; Wang, 2005, World Bank, 2004; Blumenthal and Hsiao, 2005; Liu and Mills, 1999).

The health system is usually considered costlier and more sophisticated than medically justified. This triggered government actions which eventually led to a downward trend in the share of medicines in overall health expenditures. According to Ding et al. (2016) ${ }^{4}$, over-prescription of antibiotics, injections and adrenal corticosteroids has been going down since the series of health reforms in 2009.

Amongst this series of reforms, the central government limited the drugs mark-up for public healthcare facilities. In hospitals, medical staff can now only charge 15\% over the wholesale price for drugs. This limitation in the mark-up was initially introduced to reduce the healthcare cost burden for the patient.

Public primary healthcare facilities were also given the obligation to prescribe and to dispense drugs from the National Essential Medicine List (National EML) when possible. All public primary health care settings were required to stock only drugs from the EML for the common treatable diseases. They were also required to sell them at zero-profit (the zero-profit policy where drugs on this list have to be sell at cost).

As a compensation mechanism, public health insurance schemes that cover all essential medicines, usually reimburse public health facilities at a higher reimbursement rate for drugs from this list. Yet, because of the non-centralization/non-unicity of the Chinese healthcare system, the reimbursement rate still varies between Chinese provinces.

The intention was to extend this obligation to private providers and hospitals.

\section{Structure of the medicine drug market}

In order to permit drug prices to be determined by market forces, the National Development and Reform Commission (NDRC) removed Article 55 of the Drug administration Law. From 1 June 2015, the PRC administrative bodies cease to set drug prices. Formally, the NDRC issued an " opinion on the promotion of Drug Price Reform ». ${ }^{5}$ This effort has been simultaneous to changes in both the supply and distribution structures.

\footnotetext{
4 Ding D., Q. Pan, L. Shan, C. Liu, L. Gao, Y. Hao, J. Song, N. Ning, Y. Cui, Y. Li, X. Qi, C. Liang, Q. Wu and G. Liu, "Prescribing Patterns in Outpatient Clinics of Township Hospitals in China: A Comparative Study before and after the 2009 Health System Reform"Int. J. Environ. Res. Public Health 2016, 13(7)

5 http://www.linklaters.com/Insights/AsiaNews/LinkstoChina/Pages/Challenges-pharmaceutical-companies-under-China-new-drug-pricingregime.aspx accessed September 2017
} 
Prof. Carine MILCENT

Carine.milcent@psemail.eu

CNRS - PSE

\subsection{On supply side: a very fragmented market}

The 12th five-year plan has been pointing out as a weakness the fragmentation of the pharmaceutical and medical supplies in China. There exists more than 6.000 pharmaceutical companies in China today. The 10 biggest firms only account for $15 \%$ of the total market. For consumable medical suppliers, there are more than 15,000 different companies. The 30 biggest only account for $27 \%$ of the market.

The advantage of such situation is a strong competitive environment, with no dominant player. On the flip side, it makes the control of this industry more difficult, creating risks on the quality of products that are offered to consumers. To counterbalance this, a round directives and new norms have been implemented since 2009. Among others, we can give the examples of

- In October 2014, the CFDA defined four principles for good practice for factories of medical devices ${ }^{6}$; they were integrated into the New Good Manufacturing Practice (GMP), whose revised version was released during the 17 th workshop of CFDA on December 12th, 2014 and implemented in $2015^{7}$.

- The New Edition of Pharmacopoeia published in 2015 and implemented from 2016 the increases the focus on the quality of drugs in China ${ }^{8}$.

In parallel, the 12th 5-year plan has been encouraging the concentration of the industry and the creation of a handful of financially strong pharmaceutical companies. For instance, it is interesting to note that criteria from GMP includes parameters such as the financial stability of the manufacturer. Bigger firms also tend to receive the bigger part of support and subsidies from provincial governments, such as support to $\mathrm{R} \& \mathrm{D}$ effort for instance. As a direct consequence, smaller companies are being wiped out ${ }^{9}$. From 2010 to 2013, the number of pharmaceutical companies has shrunk from 7,038 to 6,525 .

This evolution can be interpreted as a deliberate will to transform the market and concentrate the offer into a small number of bigger firms. These companies would have important assets and high R\&D capabilities, with the ability to compete with international pharmaceutical giants in all markets. Smaller players would remain, active mainly on the local markets, to foster competition while offering quality meeting the new standards set by latest norms.

\subsection{An evolving distribution landscape}

As seen previously, China is a booming market for pharmaceutical products, creating a huge retail business. According to China's Ministry of Commerce, the retail sale of drugs was 260.7 billion

\footnotetext{
6 http://eng.sfda.gov.cn/WS03/CL0757/131483.html accessed September 2017

7 http://eng.sfda.gov.cn/WS03/CL0757/112570.html accessed September 2017

8 http://eng.sfda.gov.cn/WS03/CL0757/122060.html accessed September 2017

${ }^{9}$ UBS research, 2013. http://pg.jrj.com.cn/acc/Res/CN_RES/INDUS/2013/10/2/ee2e6a3a-afcc-457b-a634-3a8827d20585.pdf accessed September 2017
} 
yuan in 2013, representing 12\% growth from the previous year. ${ }^{10}$ Since 2010, China's pharmaceutical market has been the world's second largest. ${ }^{11}$

We will study in depth the topic of the online drug market in the chapter on e-health. In short, it has been booming over recent years but not in a fully orderly fashion. Officially, only over the counter (OTC) transactions are allowed for prescription drugs. Online prescription drugs are not allowed. ${ }^{12},{ }^{13},{ }^{14}$. As a consequence, many online pharmacies do not comply with applicable Chinese laws and regulations. A study of the Alliance for safe Online Pharmacies (ASOP) ${ }^{15}$ and LogitScript review ${ }^{16}$ shows that $93 \%$ of China's online pharmacy market is operated illegally.

To improve the situation, the Chinese government has engaged in efforts since 2013 to crack down on online illegal drug sellers. ${ }^{17}$ At that time, the China Food and Drug Administration (CFDA) partnered with China's largest internet search engine, Baidu, in a collaboration in order to target the rogue pharmacy and to combat illegal online drug sales. The CFDA gave to Baidu but then after to other internet search engines, an access to its database. This allows the internet company to provide detailed information and warning messages to consumers, empowering this companies with missions of public service, with all the concerns this may raise.

The same year, the Ministry of Public Security also cracked down on illegal drug sales in an operation called «Operation Cloud». It was followed by other initiatives to curb the number of illegal manufacturers and online sale of drugs. Nowadays, such operations do not only focus now on rogue internet pharmacies but also on certified internet OTC pharmacies that engage in unlawful prescription drug sales.

A medicine tracking platform has been implemented to screen for illegal manufacturers and online sale of drugs. Because of the technology mobilized to implement such system, the tracking platform has been contracted out, to a division of the Alibaba group, Ali Health. This situation created competitive advantage considered as unfair by rivals leading to some ups (developments) and downs (suspensions) in Ali Health's role as control tower of the drug market. The main grave concern is safety of national data. ${ }^{18,19,20,21}$

\footnotetext{
10 http://sczxs.mofcom.gov.cn/article/dyplwz/bh/201406/20140600639859.shtml accessed September 2017

11 http://sczxs.mofcom.gov.cn/article/dyplwz/bh/201305/20130500145831.shtml accessed September 2017

12 http://www.scmp.com/news/china/policies-politics/article/1858097/just-what-doctor-ordered-chinas-e-tailersawait-end accessed September 2017

$13 \mathrm{http} / / /$ www.reuters.com/article/us-china-pharmaceuticals-iduskbn0ki0y220150109 accessed September 2017

14 http://www.chinadaily.com.cn/business/2015-04/03/content_19992944.htm accessed September 2017

15 The Alliance for Safe Online Pharmacies (ASOP) is a global nonprofit dedicated to protecting patient safety online. Learn more at www.safeonlinerx.com.

16 LegitScript is a company that monitors healthcare products and Internet pharmacy websites with a focus on patient safety. Learn more at www.legitscript.com.

17 https://www.nytimes.com/2015/06/22/world/asia/in-china-illegal-drugs-are-sold-online-in-an-unbridled-market.html?_r=0 accessed September 2017

18 http://www.reuters.com/article/us-china-pharmaceuticals-ali-health-idUSKCNOVXOUX accessed September 2017

19 https://www.wsj.com/articles/ali-health-swallows-bitter-pill-as-china-halts-drug-monitoring-system-1456144563 accessed September 2017
} 


\section{Regulation of the market through the EML}

\subsection{The origin of the essential medicines list (EML)}

The World Health Organization (WHO) initiated the concept of EML in 1977. The aim is to define a list of drugs and medical devices and vaccines that satisfies the basic healthcare needs of the whole population.

This definition, and as a consequence the list itself, can vary, depending on

- Criteria definition and prioritization in terms of public health relevance, evidence of efficiency, safety and comparative cost-effectiveness; ${ }^{22}$

- Local specificities

- In China, there is a national list alongside provincial lists.

The essential drugs on the list are supposed to be available at all times and everywhere, in adequate amounts, in appropriate dosage forms, with assured quality and sufficient information, and at a price affordable for the individual, the household and the community.

This obviously requires a reasonably structured healthcare system to work. It also assumes an appropriate national legislation for ensuring rational drug use.

A certain degree of structure of the healthcare system: the distribution system is one of the keys for the efficient implementation of such list. It often appears to be a challenge across most countries and China makes no exception to some extent.

Rational drug use: this list supposes a control of the demand. An explosion of the demand will jeopardize the availability of drugs on the list.

Role of patent and licensing medicines: The patent can be a limit to the availability of the drugs. With the generic drugs, licensing medicines may ensure the level of quality. In some countries like India or Indonesia, the government has imposed compulsory licensing and price control to ensure better affordability and availability.

Affordability: the price is a key variable for the availability of the drugs in this EML. However, this constraint can be solved by a health insurance. A low out-of-pocket ensures the affordability, whatever the initial price and the level of reimbursement. In China, drugs in the EML are reimbursed by the three public health insurance schemes that cover $95 \%$ of the population.

This list has now been adopted by numerous countries and international organizations (United Nations Children's Funds _ UNICEF; Doctor without borders (Médecins sans frontière). ${ }^{23}$

\footnotetext{
20 http://www.scmp.com/business/companies/article/1897939/alibaba-health-care-unit-stumbles-2016-deal-online-pharmacy accessed September 2017

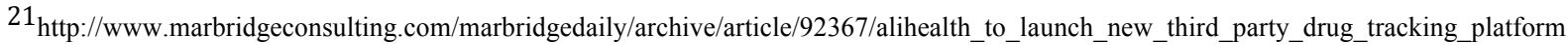
accessed September 2017

22 www.who.int/topics/essential_medicines/en/

accessed September 2017
} 
Prof. Carine MILCENT

Carine.milcent@psemail.eu

CNRS - PSE

In China, the Ministry of Health $(\mathrm{MoH})$ initiated the first EML in 1982, including some traditional Chinese medicine recipes. In 2004, the EML included 2,033 products, including 1,260 Chinese herbal preparations and 773 chemical and biological medicines. Since then, new versions of the EML have regularly been published. ${ }^{24,25}$, with updated coming usually every two or three years. The integration of treatment for heavier pathologies is currently under study.

Similarly, medical devices have their own list, established by MoH. The 2009-2011 National Class II Large-Scale Medical Device Allocation Plan has as an objective to regulate the number of medical devices ${ }^{26}$.

On top of this, prices of some health products have also been capped. NDRC and its regional bureaus set a maximum authorized price for roughly 2,700 products.

For products that are also in the EML, retail price is supposed to be below the max price fixed by NDRC.

\subsection{EML and public insurance schemes}

Until 2009, the EML was not taken into account into the reimbursement schemes of health insurances. At that time, a sub-list of 307 drugs including 102 from Chinese traditional medicine was established. Drugs on that list should be covered by public health insurance and their price should be capped. From then, the use of these EML drugs was imposed by the central government for public healthcare facilities.

This has a double objective: on one side, to improve the control of cost, on the other side, to give incentive to the population to subscribe to a public insurance scheme: Individuals covered by the Urban Employees Basic Medical Insurance or Urban Residents Basic Medical Insurance can buy medicines in hospitals with their insurance card. On the other, patients without these policies, out-of-pocket payments for medicines are high, which badly impedes access, financial protection and equity.

\subsection{Central and local responsibilities regarding the $\mathrm{EML}^{27}$}

The part of 2009-reform regarding EML and its subsequent evolutions have been managed by different agencies under the leading group's supervision. ${ }^{28}$

\footnotetext{
23 Shekhar Kar S., Sekhar Pradhan H., Prasad Mohanta G. « Concept of Essential Medicines and Rational Use in Public Health » Indian Journal Community Medicine, 2010.

24 S. Barber, B. Huang, B. Santoso, R. Laing, V. Paris, C. Wu, "The reform of the essential medicines system in China: a comprehensive approach to universal coverage”, WHO, 2013.

25 D. Wang, X. Zhang, “The selection of essential medicines in China: progress and the way forward”, Southern Med Review, 2011

26 Christine Kahler, China’s Healthcare Reform: How far Hat it Come? 2011 January1 China Business Review. http:/www.chinabusinessreview.com/chinas-healthcare-reform-how-far-has-it-come/ Accessed September 2017

27 Institute for Healthcare Informatics _ IMS, “Understanding the Role and Use of Essential Medicines Lists », 2015
} 
- The Ministry of Health is responsible for healthcare services delivery including drugs;

- The National Development and Reform Commission deals with pricing rules and regulations including the National Reimbursement Drug list;

- The Ministry of Human Resources and Social Security manages the Government-funded health insurance that reimburses the sub-list of the EML drugs;

- The State Food and Drug Administration is responsible for health-related product safety;

- The China Insurance Regulatory Commission manages commercial health insurances.

The $\mathrm{MoH}$ is responsible for the selection of essential medicines for inclusion in the national essential drugs list. The $\mathrm{MoH}$ forms a committee consisting of experts in the field of medicine, pharmacy, health insurance, health management, and pricing. These experts are divided into two mutually exclusive groups, a consulting group and a review group.

- The consulting group: the experts evaluate drugs and give their opinions on the drugs. These opinions will be used to defined the candidate drugs list;

- The review group: these experts vote which drugs have to be included in the draft list using the candidate list.

From the draft list, the government departments give approval and comments on each drug. Some suggestions and comments can be added from the public and the stakeholders. Only after, the managing authority gives the final approval.

Each provincial government has the authority to include more drugs on the EML at provincial level and to publish a provincial drug list. However, provincial governments do not have the authority to remove items from the national drug list. ${ }^{29}$

Practically, provincial health administrations define province-specific essential drug lists relevant to the regional context. All the drugs on these lists are then compiled into the national essential drug list. All government sponsored primary facilities have been using essential drugs lists since the end of 2011. Public insurance compensation for essential drugs is $10-15 \%$ higher than for non-essential drugs. For Traditional Chinese Medicine (TCM), the compensation ratio is raised by $5-10 \%$. The number of national essential drugs for primary level issues in 2009 was 307 of which 102 were Traditional Chinese Medicine.

As a result of this complex process, a study over 22 provinces shows a positive correlation between the level of wealth of the province and the number of drugs added to the list. ${ }^{30}$ This result highlights the inequalities that can exist due to the non-unicity of the Chinese health system. Other decentralized systems, such as Switzerland for instance, have introduced equalization mechanisms between wealthier and poorer areas, but such a mechanism does not exist between the provinces of China.

\footnotetext{
28 As explained in a previous Chapter, the State Council established the leading Group for Coordination Healthcare System Reform, an interagency team headed by Vice Premier and administrated by NDRC.

${ }^{29}$ L. Wang, E. Ma, W. Xu, "Comparative Analyses of China National \&Twenty two selected Provincial Essential Medicines Lists to the WHO 2011 Model List", WHO, 2011

30 Wang D, Zhang X. The selection of national essential medicines in China: progress and the way forward. Southern Med Review. 2011;4:22-8.
} 
Prof. Carine MILCENT

Carine.milcent@psemail.eu

CNRS - PSE

\subsection{The Reform of the EML}

Table 1: EML and healthcare system in China

\begin{tabular}{|c|c|}
\hline Area of reform & Impact on essential medicines \\
\hline $\begin{array}{l}\text { Social security and } \\
\text { insurance }\end{array}$ & $\begin{array}{l}\text { - Large-scale in the number of people covered under formal insurance } \\
\text { programs ( } 93.0 \% \text { coverage in 2011). Insurance reimbursement lists are } \\
\text { required to incorporate the medicines on the Essential medicines lists } \\
\text { (EML) at central and provincial levels, at higher reimbursement rates } \\
\text { compared with medicines not on the EML } \\
\text { - Inpatient insurance reimbursement rates rose steadily, averaging } 46.9 \% \\
\text { in 2011, including medicines and service fees. } \\
\text { - Per capita premiums for basic health insurance programs to increase } \\
\text { to } 360 \text { Yuan (US } \$ 57) \text { per person by 2015, from about US } \$ 32 \text { in } 2010 \\
\rightarrow \text { Essential medicines available at cost } \\
\rightarrow \text { Inpatients are reimbursed for essential medicines at higher rates than non-essential } \\
\text { medicines }\end{array}$ \\
\hline Service delivery & $\begin{array}{l}\text { - Reconstruction of the primary care system, including some } 2200 \\
\text { - } \text { In governty hospitals and } 33000 \text { urban and rural primary care facilities. } \\
\text { reform under way to replace revenue from medicines sales to fund } \\
\text { operational costs, through increased insurance and government } \\
\text { subsidies } \\
\text { - At all government-run primary care facilities, essential medicines are } \\
\text { provided at cost (zero profit mark-up) } \\
\circ \quad \text { In urban areas } \\
\circ \quad \text { In rural areas } \\
\text { - Zero mark-up has been expanded as pilot program to selected } \\
\circ \quad \text { village clinics, } \\
\circ \text { non-government run primary care facilities, } \\
\circ \text { county hospitals } \\
\text { Link between volume of prescription and profit: Prescribing and } \\
\text { physician remuneration have been disconnected in many primary care } \\
\text { facilities. The expected effect is to reduce the incentives for over- } \\
\text { prescription. } \\
\text { Centralized procurement and bidding platforms implemented at } \\
\text { provincial level, including online purchasing. } \\
\text { Efforts are made to reduce the number of distributors and } \\
\text { mark-ups in the distribution chain } \\
\circ \quad \text { The two-envelop system: the supplier has to submit two sets } \\
\text { of documents. One is for the quality and performance } \\
\text { standards of the pharmaceutical product. The other document } \\
\text { is for the pricing proposal. The commercial bid cannot be } \\
\text { considered if the document on the drug's quality is not }\end{array}$ \\
\hline
\end{tabular}




\begin{tabular}{|c|c|}
\hline & $\begin{array}{l}\text { validated by local authorities. } \\
\text { This two-envelop system supposes that the authorities have } \\
\text { the ability to evaluate the drugs and the resources in terms of } \\
\text { staff qualification, time, and available information. } \\
\text { The implementation at provincial level may introduce } \\
\text { geographical disparities in the quality of drugs offered on the } \\
\text { market. } \\
\text { However, this process ensures at least a certain level of } \\
\text { quality, under the tendering system prior to consideration of } \\
\text { the commercial bid. } \\
\text { Release of pricing data to foster price transparency } \\
\text { Digital as an efficiency tool } \\
\text { Online bidding platforms have been set up to facilitate the } \\
\text { purchase of medicines from the EML at the best cost } \\
\text { possible. The objective is to go around the de facto monopoly } \\
\text { situation of some wholesalers at local level. These platforms } \\
\text { make it possible to regroup all sellers and buyers on one } \\
\text { market when they were previously scattered, increasing the } \\
\text { level of competition. } \\
\text { Limit of the competition } \\
\text { In a static context, the bidding process allows to select the } \\
\text { most efficient provider: the one proposing the lowest possible } \\
\text { price at a level of quality requiring the performance standards. } \\
\text { The two-envelope system allows the local authorities to } \\
\text { ensure the quality standards } \\
\text { This principle supposes that supply is in adequate quantity } \\
\text { and that the number of suppliers remains sufficient to ensure } \\
\text { the sustainability of the competitive situation. } \\
\text { In a dynamic process, the different rounds of bidding tend to } \\
\text { a decreased competitive market. It leads to reduce the number } \\
\text { of producers. The result is often a situation of oligopolistic } \\
\text { market or, in some cases, monopolistic market. Besides, fewer } \\
\text { firms may imply a decreased supply. The consequence may be } \\
\text { an insufficient quantity of the EML drugs. For instance, in } \\
\text { Fuijian province, } 42 \text { products on the EML could not be easily } \\
\text { procured.31 According to the authors one of the main reasons } \\
\text { is the shortage in the number of producers at the proposed } \\
\text { price. }\end{array}$ \\
\hline Public health & $\begin{array}{l}\text { Ten categories of basic public health services have been implemented, } \\
\text { including expanded access for Hepatitis B vaccines and cervical and breast } \\
\text { cancer screening, through a per capita subsidy ( } 40 \mathrm{RMB}) \text { to primary care } \\
\text { facilities. } \\
\text { The public health subsidy replaces to a large extent the revenue lost through } \\
\text { the zero mark-up policy for essential medicines, and covers a large share of } \\
\text { operational costs at township hospitals, village clinics, and community health } \\
\text { services centers. }\end{array}$ \\
\hline $\begin{array}{l}\text { Public hospital reform } \\
\text { on pilot basis }\end{array}$ & $\begin{array}{l}17 \text { municipalities and } 37 \text { provincial cities were designated to undertake hospital } \\
\text { reform on a pilot basis, to reduce the reliance on medicine sales as a major }\end{array}$ \\
\hline
\end{tabular}

\footnotetext{
${ }^{31}$ Barber, S., Baobin Huang, Budiono Santoso, Richard Laing, Valerie Paris, Chunfu Wu "The reform of the essential medicines system in China: a comprehensive approach to universal coverage"Journal of Global Health June 2013 • Vol. 3 No. 1
} 
Prof. Carine MILCENT

Carine.milcent@psemail.eu

CNRS - PSE

\begin{tabular}{|l|l|}
\hline & $\begin{array}{l}\text { source of revenues. The main activities include provider payment reform } \\
\text { (mainly DRGs and case based payments) and clinical pathways, setting fixed } \\
\text { prescription fees, and setting up independent pharmaceutical distribution }\end{array}$ \\
networks. In 300 county hospitals in 2012, it is proposed to eliminate \\
completely the medicines bonus policy, whereby staff are rewarded for over- \\
prescription.
\end{tabular}

Source: http://www.jogh.org/documents/issue201301/V3_Barber.pdf accessed September 2017

\subsection{Impact of the EML in China}

The implementation of the EML seems to have reached it goal. From 2008 to 2011, medicine expenditures as a percent of the total health expenditures fell from $41.5 \%$ to $37.6 \%$. Figure 1 displays the evolution of the public healthcare expenditure, the private healthcare expenditure and the total expenditure on pharmaceuticals as a percent of the total health expenditure.

Figure 1: Private and general government health expenditures, and percent of total health spending devoted to pharmaceuticals, 1995-2010

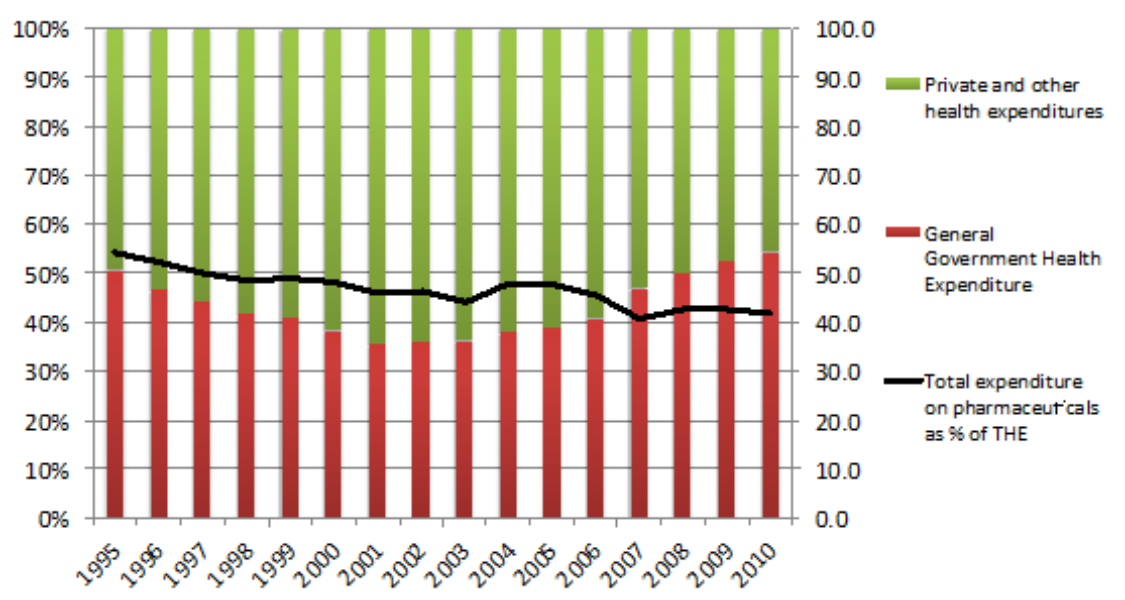

Source: China National Health Economics Institute. National health accounts report 2012. Beijing: Ministry of Health, People's Republic of China, 2012. \& http://www.jogh.org/documents/issue201301/V3_Barber.pdf access September 2017

On the ground, results appear to be a bit more mixed. A study from Zhang et al (2015) ${ }^{32}$, realized in six different counties shows this heterogeneous situation. For instance, the authors found that no non-essential drugs were used in the village clinics in the county of Changshu. In parallel, they observed that in Maiji district and Acheng district, non-essential drugs were still sold, and with a mark-up. They also note village doctors are earning 3,000RMB in average as compensation for using EML drugs in Changshu whereas this amount was only a few hundred RMB in Maiji. Hence, the amount of funds and allocation largely differed from one location to the other. Besides, according to the same paper, it is shown that supply of drugs differs depending on the type of geographical location. Re-supplying remote or mountain areas being not worth the effort in terms of cost, supply is often insufficient.

\footnotetext{
${ }^{32}$ Zhang S.,W. Zhang, H. Zhou, H. Xu, Z. Qu, M. Guo, F. Wang, Y. Zhong, L. Gu, X. Liang, Z. Sa, X. Wang, and D. Tian (2015) "How China's new health reform influences village doctors' income structure: evidence from a qualitative study in six counties in China ", Human Resources for Health, 13(26)
} 
The way the EML policy is perceived by patients have been studied in details in an article from Song et al. (2016) ${ }^{33}$. Usually speaking, patients have little awareness of this ongoing reform. Nonetheless, they tend to notice a decrease in price and increase in quality of medicines that are listed on the EML.

According to another study from $2015^{34}$, the EML deteriorated the village doctors' satisfaction over their employment. The reasons given in the paper is that integrated management of village doctors activities by township-level staff has reduced their independence, and different counties' economic status and health reform processes have also led to inconsistencies in village doctors billing and revenues.

On top of allowing universal access to essential drugs, another goal of the EML is to improve rational drug use, especially in primary health care facilities. According to the World Health Organization (WHO) in 2002, over the world, more than 50\% of all drugs prescribed, dispensed or sold are inappropriate. More than $50 \%$ of patients failed to take their medicines correctly. A 2014 study in township health center providing health care services for a large rural population showed that this EML list tends to improve rational medicine use in China. However, the over prescription of antibiotics and injections remain common. ${ }^{35}$ What about pricing, how has it been impacted by the EML? According to the authorities, the price drugs on the list has been decreasing. ${ }^{36}$ This seems to be support by other studies. ${ }^{37}$ According to Song et al. (2014)'s study $^{38}$, imposing the use of the drugs from the national list led to price reduction for essential medicines.

However, more-expensive drugs were often preferred in the post-reform period. Besides, most public primary healthcare facilities started to earn smaller revenues to the mandatory implementation of the IML, as compensation mechanisms from the public health insurances were not sufficient. Some centers saw their debt pile up. In July 2011, the State Council, the National Development and Reform Commission and the Ministry of Health took official steps to address this and instructed provinces to set up plans to financial situation of health institutions on a sounder foot.

\footnotetext{
${ }^{33}$ Song Y., Y.Bian* and L. Li (2016) "Current perspectives on China's national essential medicine system: primary care provider and patient views", BMC Health Services Research, 16(30)

34 Zhang S.,W. Zhang, H. Zhou, H. Xu, Z. Qu, M. Guo, F. Wang, Y. Zhong, L. Gu, X. Liang, Z. Sa, X. Wang, and D. Tian (2015) "How China's new health reform influences village doctors' income structure: evidence from a qualitative study in six counties in China ", Human Resources for Health, 13(26)

35 Song Y., Y. Bian, M. Petzold, L. Li, A. Yin “The impact of China's national essential medicine system on improving rational drug use in primary health care facilities: an empirical study in four provinces" BMC Health Services Research 2014, 14:507 http://www.biomedcentral.com/1472-6963/14/507 accessed September 2017

36 Zhang Xiang. More measures needed to deepen healthcare reform in China: vice premier. Xinhua English News. November 11.

${ }^{37}$ Li Y, Ying C, Sufang G, Brant P, Bin L, Hipgrave D. Evaluation, in three provinces, of the introduction and impact of China's National Essential Medicines Scheme. Bull World Health Organ. 2013;91:184-94.

Yang L, Liu C, Ferrier JA, Zhou W, Zhang X. The impact of the National Essential Medicines Policy on pre- scribing behaviors in primary care facilities in Hubei province of China. Health Policy Plan. 2012.

38 Song Y., Y. Bian, M. Petzold, A. Yin “Effects of the National Essential Medicine System in reducing drug prices: An empirical study in four Chinese provinces", Journal of Pharmaceutical Policy and Practice react-text: 15 7(1):12/react-text react-text: 18 • /react-text reacttext: 19 September 2014
} 
To conclude, it is possible to say that the implementation of the EML is widely approved by consumers for its impact on both price and quality. It is also usually quite well understood on the supply side. Yet, sufficient supply seems to be a key variable for the stability of the health system that is increasingly reliant on the medicines from this list.

\section{Beyond the EML}

Since the mid 80's, hospitals have tried to modernize, to improve their level of equipment and quality, while suffering from a decreasing financial support from central and local authorities. The sale of medicine drugs and other medical supplies have gradually become one of the main sources of revenue for public hospitals. Margin rates between cost and resale prices have skyrocketed. All policies implemented since 2009 are aiming at reducing this mark-up.

Beyond EML, hospitals must now keep their margin level below 15\% on wholesale price, which has heavily impacted their financial stability. The compensation has been delegated to provincial governments, whose wealth level can be very different. This raises an issue of inequality to healthcare access or inequality of quality of healthcare.

Hospitals also tend to set-up other self-funding strategies. One of them is the increase in the turnover of health services through a larger number of diagnosis and procedures per patient. Although this strategy is more difficult to detect than medicine price increase, even before 2009 some empirical studies ${ }^{39}$ were showing that the Chinese health system's consumption of certain acts and procedures was already excessive. Another strategy is over-prescription. In 2009, the cost of medicine drugs accounted or $41 \%$ of total medical costs. One of the ways to contain such strategies is to implement a prospective payment system based on pathologies. Specifically, for hospital stays, a Chinese version of the Diagnostics Related Groups (DRG) may be an answer. Each stay is associated to a DRG and a specific fee is associated to a specific DRG. The result is then at any given time, the fee payment is disconnected from the actual procedures and diagnosis performed on the patient during his stay. This scheme of payment is widely used in the OECD countries, but is at pilot stage in China. ${ }^{40}$

\footnotetext{
39 Eggleston, K., Li, L. and Meng, Q., Lindelow M. and Wagstaff, A., "Health Service Delivery in China: A Literature Review", (2008), Health Economics 17, 149-165.
} 